\title{
A SEMÂNTICA E O ENSINO DE LÍNGUA PORTUGUESA
}

\author{
Karen Neves Olivan ${ }^{1}$ \\ Mestranda em Linguística - Universidade Federal de Santa Catarina
}

\begin{abstract}
Resumo
Demonstrar a necessidade de enfoque semântico nas atividades contempladas no ensino de Língua Portuguesa é o ponto gerador deste artigo, que visa à apresentação de possibilidades de inserção dessa área no planejamento das aulas, a partir da análise de materiais didáticos. Como aporte teórico, apresenta-se a conceituação de elementos semânticos tais como relações de sinonímia, ambiguidade e operadores argumentativos. De forma intercalada à descrição teórica, apresenta-se a análise de doze livros da coletânea Português: linguagens, de Cereja e Magalhães, elaborados em consonância aos pressupostos teórico-metodológicos dos Parâmetros Curriculares Nacionais (PCNs). Como conclusão, sugere-se a extrapolação dos exercícios de cunho morfológico e sintático para atividades que propiciam maior reflexão sobre a língua, o que será possível pela ampliação do espaço destinado à semântica na disciplina.
\end{abstract}

Palavras-chave: Ensino. Livro didático. Semântica. Ambiguidade. Relações de sinonímia.

\begin{abstract}
Demonstrating the need on the semantic focus on the activities present in teaching Portuguese is the begetting point of this article, which aims at demonstrating possibilities of insertion of this area in class planning, based on the analysis of didactic material. As the theoretical bases, the conceptions of semantic elements, such as the synonymic relations, ambiguity and supportive operators, are presented. In parallel to the theoretical description, the analysis of twelve books from the set: Português: linguagens, by Cereja and Magalhães, elaborated according to the theoreticalmethodological requirements of the National Curricular Parameters (PCNs) is presented. As a conclusion, the extrapolation of the morphological and syntactical exercises for activities which provide a deeper reflection on the language is suggested, which will be feasible through the broadening of the area destined to semantics on the subject.
\end{abstract}

Keywords: Teaching. Didactic books. Semantics. Ambiguity. Synonymic relations.

\section{CONSIDERAÇÕES INICIAIS}

Segundo Pereira e Henriques (2002), a linguística entrou para o currículo universitário há apenas três décadas, o que significa que grande parte dos professores de Língua Portuguesa ativos no mercado de trabalho tiveram, em sua formação, pouco contato com essa área de conhecimento. Além disso, ao ingressarem nesse mercado, depararam-se com uma rede de ensino enraizada na tradição e adepta às práticas

\footnotetext{
${ }^{1}$ Pós-graduanda em Estudos Linguísticos e Literários Aplicados ao Ensino pela Universidade do Sul de Santa Catarina (UNISUL), licenciada em Letras Português/Inglês pela UNISUL. Professora da rede particular de ensino em Santa Catarina.
} 
repetitivas do ensino gramatical, o que provocava - e ainda provoca - um bloqueio no ímpeto de afrontar essa tradição e de suportar as pressões sociais ante as mudanças.

Entretanto, há cerca de dez anos, com a criação dos Parâmetros Curriculares Nacionais - PCNs -, a linguística ganhou destaque no conteúdo programático, visto que ela propõe um trabalho cujo enfoque é aprimorar a capacidade de compreensão e expressão dos alunos em situações de comunicação, isto é, facilitar sua interação na sociedade.

A proposta dos parâmetros não despreza o ensino da gramática normativa, mas sim questiona a forma como esta vem sendo trabalhada e propõe um ensino de Língua Portuguesa com vistas na dimensão semântica e/ou discursiva da língua, afinal, é também através do estudo da semântica, especificamente a semântica da enunciação, que se consegue, a partir de situações concretas de comunicação, ampliar a abordagem gramatical. Logo, a presença da semântica no ensino de Língua Portuguesa tem como objetivo promover a reflexão sobre os recursos semântico-expressivos da língua, desenvolvendo, consequentemente, a competência linguística e comunicativa do aluno e esclarecendo os mecanismos de funcionamento da língua.

Considerando isso como um pressuposto estabelecido nos parâmetros, cabe acrescentar ainda que "[...] determinados objetivos só podem ser conquistados se os conteúdos tiverem tratamento didático específico [...]” (BRASIL, 1997, p. 37), tratamento esse que pode ser verificado por meio de pesquisa em materiais pedagógicos.

Por essa razão, neste artigo, buscamos investigar a inserção de atividades que contemplem os estudos semânticos propostas em livros didáticos no Ensino Fundamental e Médio do sistema brasileiro de ensino.

\section{CONTEXTUALIZANDO O ENSINO DA LÍNGUA MATERNA}

Nos fóruns de Educação, quando se discutem os necessários avanços no ensino básico, a disciplina Língua Portuguesa vem sendo apontada como uma área que ainda carece de reformulações. Nesse sentido, esperam-se contribuições das ciências linguísticas, que já vêm exercendo influência nessa área, mesmo que os resultados esperados sejam alcançados muito lentamente.

Segundo Ilari (2003), essa influência não chegou a modificar totalmente a proposta pedagógica para o ensino da língua materna, uma vez que havia uma crença de que a Linguística substituiria a Gramática e a Filologia, renovando, assim, o ensino da língua.

Atualmente, a atuação da Linguística no ensino é delicada, pois, ainda que historicamente ela tenha ganhado espaço no ensino, devido à sua abrangência, sua aplicação não tem sido suficientemente eficaz para surtir os resultados esperados. Portanto, é pertinente retomar um pouco da história da atuação da Linguística no ensino.

A Linguística vem contribuindo para o ensino de Língua Portuguesa desde a década de 80, quando os estudos de Sociolinguística, Psicolinguística, Linguística Textual, Pragmática e Análise do Discurso passaram a ser "aplicados" ao ensino da língua materna nas escolas, através de interferências bastante significativas. 
Inicialmente, segundo Soares (2002, p. 171), a Sociolinguística chamou a atenção da escola para a multiplicação das variantes linguísticas neste contexto com "[...] a democratização da escola e, portanto, do acesso de alunos pertencentes às camadas populares à escolarização [...]”, implicando, assim, mudanças no ensino de Língua Portuguesa que, anteriormente dirigido às camadas privilegiadas da população, volta-se a alunos que trazem para a sala de aula uma maior heterogeneidade linguística, pois reforça a atenção dos professores à diversidade linguística já existente e agora ampliada, exigindo, então, não só uma nova postura desses professores, como também uma adaptação dos conteúdos e, consequentemente, a necessidade de uma nova metodologia para a disciplina.

Em seguida, a Linguística trouxe novas concepções da gramática do português, a qual, devido a seus estudos de descrição da língua, sugere não apenas o ensino da modalidade escrita, mas também da língua falada.

Recentemente, a Linguística Textual veio ampliar essa nova concepção da função da gramática para fins didáticos, evidenciando, segundo Soares (2002, p. 172):

[...] a necessidade e conveniência de que essa gramática não se limite às estruturas fonológicas e morfossintáticas, mas chegue ao texto [...]. Nesse mesmo sentido, a Semântica, em suas tendências mais recentes, vem associando-se à Lingüística Textual, para trazer uma nova maneira de tratar a expressão e a compreensão tanto na modalidade oral quanto na escrita.

Provavelmente ainda mais fundamental que as contribuições acima tem sido a influência que vem sendo exercida sobre a disciplina Português concomitantemente pela Pragmática, pela Teoria da Enunciação e pela Análise do Discurso, influência fundamental, porque traz basicamente uma nova concepção de língua: uma concepção que vê a língua como enunciação, não apenas como comunicação, que, portanto, inclui as relações da língua com aqueles que a utilizam, com o contexto em que é utilizada, com as condições sociais e históricas de sua utilização. Essa nova concepção vem alterando em sua essência o ensino da leitura, da escrita, as atividades de prática da oralidade e, até mesmo, o ensino da gramática.

Considerando o contexto atual, em que se mesclam as consequências dos avanços apresentados e as dificuldades ainda visíveis tanto na formação do profissional, quanto na seleção dos conteúdos abordados e na escolha por uma opção metodológica, cabe questionar qual tem sido e qual poderá ser o papel da Semântica na disciplina Língua Portuguesa.

Nos Parâmetros Curriculares Nacionais, no capítulo introdutório, denominado Caracterização da área da língua portuguesa, encontramos os pressupostos básicos sobre o ensino da língua materna, o qual deve nortear todos os ciclos do Ensino Fundamental e Médio. Dessa introdução, pode-se resumir que é necessário - e urgente - que a escola promova sua ampliação propiciando ao aluno a capacidade de interpretar diferentes textos que circulam socialmente, de assumir a palavra e, como cidadão, de produzir textos eficazes nas mais variadas situações. Assim, torna-se fundamental: 
- trabalhar a diversidade de texto, na perspectiva de gêneros textuais;

- contemplar a diversidade de dialetos, considerando várias modalidades de uso da língua em diversos contextos;

- possibilitar a prática de reflexão sobra a língua, seja por atividades epilinguísticas ou metalinguísticas.

Essa concepção permite e torna necessário abordar alguns conteúdos específicos da Semântica, que poderiam contribuir tanto para o desenvolvimento da interpretação quanto para o da capacidade de análise linguística.

Não se trata de propor ao aluno do ensino básico um estudo exaustivo da semântica, seja na linha formal, argumentativa ou cognitiva, mas sim de repensar os conteúdos, muitas vezes já estudados apenas no nível da sintaxe, reabordando-os com um enfoque semântico.

Em um breve levantamento de como tradicionalmente se formaliza o estudo da gramática na escola, podemos afirmar que se trata de um percurso o qual se inicia na Fonética/Fonologia, quando o foco são questões como tonicidade e separação silábica, passa para a Morfologia, a partir do estudo da formação das palavras e das classes gramaticais, e avança para a Sintaxe, com o objetivo de se fazer um exaustivo estudo dos períodos simples e compostos, visando principalmente ao aprendizado da nomenclatura. Em paralelo à gramática, encontram-se as atividades de leitura e de produção textual, na maior parte das vezes, postas como áreas de estudo isoladas.

É relevante, então, dizer que a Semântica pouco se faz presente, e isso é sistemático, tanto nos compêndios gramaticais quanto nos materiais didáticos e nos planejamentos escolares. Alguns tópicos específicos da Semântica são tratados superficialmente, como a relação de sinonímia e antonímia entre as palavras e o fenômeno da ambiguidade, que parece ser mais posto como um defeito de escrita do que como um recurso intencional.

Este trabalho, como posto na introdução, delimita como objeto de análise apenas o material didático, portanto é a partir deste levantamento e desta análise que se pautam as considerações sobre a presença ou ausência da semântica no ensino.

Foram pesquisadas coleções de dez diferentes autores ${ }^{2}$, indicados para o Ensino Fundamental e Médio. No entanto, mesmo que a maioria dos autores anunciem sua

\footnotetext{
${ }^{2}$ GARCIA, Eliana. Língua e linguagem. $3^{\mathrm{a}}$ ed. São Paulo: Saraiva, 2005. (1 ${ }^{\mathrm{a}}$ a $4^{\mathrm{a}}$ séries) / MARSICO, Maria Teresa; CUNHA, Maria do Carmo Tavares; ANTUNES, Maria Elisabete Martins; CARVALHO NETO, Armando Coelho. Agora eu sei: Língua Portuguesa. São Paulo: Scipione, 2007. (1 a a $4^{\mathrm{a}}$ séries) / MIRANDA, Cláudia; Lopes, Angélica; RODRIGUES, Vera Lúcia. Língua Portuguesa. Série Vivência e construção. $2^{\mathrm{a}}$ ed. São Paulo: Ática, 2004. (1 $1^{\mathrm{a}}$ a $4^{\mathrm{a}}$ séries) / CEREJA, William Roberto; MAGALHÃES, Thereza Cochar. Gramática reflexiva. $3^{\mathrm{a}}$ ed. São Paulo: Atual, 2003. (5 a a $8^{\mathrm{a}}$ séries) / JORDÃO, Rose; RODRIGUES, Fátima. Exercícios de gramática reflexiva: ensino fundamental. São Paulo: Moderna, 2002. ( $5^{\mathrm{a}}$ a $8^{\mathrm{a}}$ séries) / MESQUITA, Roberto Melo; MARTOS, Cloder Rivas. Gramática pedagógica. 29a ed. São Paulo: Saraiva, 2005. (5 a a $8^{a}$ séries) / SARMENTO, Leila Lauar. Português: leitura, produção, gramática. São Paulo: Moderna, 2002. (5 a ${ }^{a}$ séries) / MESQUITA, Roberto de Melo. Gramática da Língua Portuguesa. 8a ed. São Paulo: Saraiva, 2005 (Ensino Médio) / CEREJA, William Roberto; MAGALHÃES, Thereza Cochar. Gramática reflexiva: texto, semântica e interação. 2a ed. São Paulo: Atual, 2005. (Ensino Médio) / CEREJA, William Roberto; MAGALHÃES, Thereza Cochar. Português: linguagens. $3^{\mathrm{a}}$ ed. São Paulo: Atual, 2006. (Ensino Fundamental e Médio).
} 
preocupação com a semântica, que sempre aparece em títulos de seções e nas orientações aos professores, o conteúdo abordado não equivale exatamente aos conteúdos de que trata a área da Semântica. Na verdade, encontramos tal abordagem em apenas quatro coleções: Gramática pedagógica e Gramática da Língua Portuguesa, de Mesquista e Martos; Português: linguagens e Gramática reflexiva: texto, semântica e interação, de Cereja e Magalhães.

Nas primeiras, o tratamento da semântica é feito de modo objetivo, com poucos exemplos e sem qualquer atividade para compreensão e assimilação dos conceitos, que são apresentados no apêndice. Nas últimas, a abordagem contempla os principais tópicos semânticos de forma clara e rica em exemplos próximos da realidade do aluno/leitor, além de propor uma série de atividades reflexivas, que incorporam conceitos da semântica na prática de leitura, interpretação e análise linguística.

Considerando que, no amplo contexto da reformulação da qual carece a disciplina de Língua Portuguesa, um ponto a ser priorizado deve ser maior inserção da área da semântica, segue, nas próximas seções, a apresentação de alguns tópicos específicos da semântica lexical, apontando, a partir do tratamento dado por Cereja e Magalhães, a possibilidade de se estudar tal conteúdo desde o nível básico de ensino.

\section{APROXIMANDO OS SENTIDOS: RELAÇÕES DE SINONÍMIA}

Segundo Ilari e Geraldi (1987, p. 43), “[...] sinonímia é identidade de significação”, ou seja, identidade de sentido, que pode ser classificada de sinonímia lexical, estrutural ou lexical e estrutural. Cabe investigar como tal fenômeno pode ser abordado com fins didáticos.

Da primeira coleção analisada, Português: linguagens, podemos afirmar que, para as séries iniciais do Ensino Fundamental, a obra busca, principalmente, despertar o aluno/leitor para a interpretação do texto a partir da compreensão das palavras. Neste sentido, já no volume da $1^{\text {a }}$ série (p. 113), os autores trazem o conceito de sinonímia: "Palavras que têm o mesmo sentido ou um sentido parecido são sinônimas uma da outra”. Interessante perceber que, mesmo apresentando um conceito simplificado, os autores acrescentam ao leitor a informação de que as palavras têm multiplicidade de sentidos, o que desestabiliza a ideia de sinônimos perfeitos.

Conforme Ilari e Geraldi (1987), para que ocorra a sinonímia lexical, é preciso que duas palavras sinônimas sejam empregadas de modo que contribuam com o mesmo sentido na frase, isto é, sem que esta passe de falsa a verdadeira, ou vice-versa. Logo, devemos sempre pensar a sinonímia dentro do contexto em que as palavras são empregadas.

Na mesma direção, Murphy (2000) argumenta que essa relação não é tão simples, pois o que é visto como relações de sentidos entre palavras (dentro do domínio do conteúdo lexical) são, na verdade, relações que envolvem fatores discursivos e baseados em relevância (dentro do domínio da pragmática).

Assim, não se pode pensar na existência de sinônimos perfeitos, pois um termo, por possuir mais de um sentido, pode ter uma equivalência adequada somente a um dos seus sentidos e não à totalidade deles. 
Na sequência, a partir do volume destinado à quinta série, os autores, em uma tentativa de sistematizar mais os possíveis conteúdos a serem abordados, definem uma seção, presente em todos os capítulos, denominada Semântica e Discurso. O propósito dessas seções é explorar algum aspecto do sentido a partir da leitura de um texto. Desse modo, os textos variam em gêneros como cartuns, tiras, histórias em quadrinhos, poemas, anúncios e outros, sendo a maioria específicos dos discursos humorísticos e publicitários, pois, além de serem textos sofisticados em recursos semânticos, estão presentes no cotidiano do aluno/leitor. Em muitas dessas seções, a proposta de interpretação pauta-se na identificação da linguagem não verbal, em comparação à verbal, mostrando que inclusive a aproximação imagem vs. enunciado provoca uma relação de semelhança. Em outras, explora-se a compreensão do sentido metafórico de expressões da língua.

Vejamos o texto presente em uma atividade da $5^{\mathrm{a}}$ série, a partir de uma tira de Laerte, publicada em Suriá, a garota do circo:

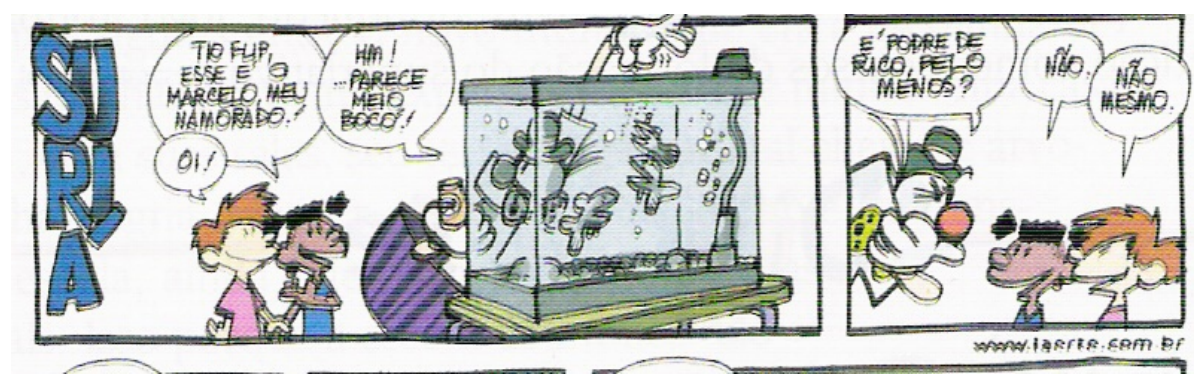

No $1^{\circ}$ quadrinho, Tio Flip faz um comentário sobre Marcelo. Qual é o sentido da expressão meio bocó?

No $2^{\circ}$ quadrinho:

a) Qual é o sentido da expressão podre de rico?

1. Fonte: Cereja e Magalhães. Português: linguagens - 5a série - p. 151.

Percebemos que esta proposta leva o aluno/leitor a pensar em substituição vocabular, cuidando do sentido contextual, além de instigá-lo a tomar conhecimento da diversidade de expressões da nossa língua.

Ainda em relação à sinonímia, estendendo do nível lexical para o nível estrutural, encontramos alguns exercícios que visam à percepção da diferença de sentidos em relação à diferença estrutural dos enunciados, como observamos em atividade proposta à $7^{\mathrm{a}}$ série, a partir do enunciado presente em um anúncio de uma série de livros - Série Cidadania: 


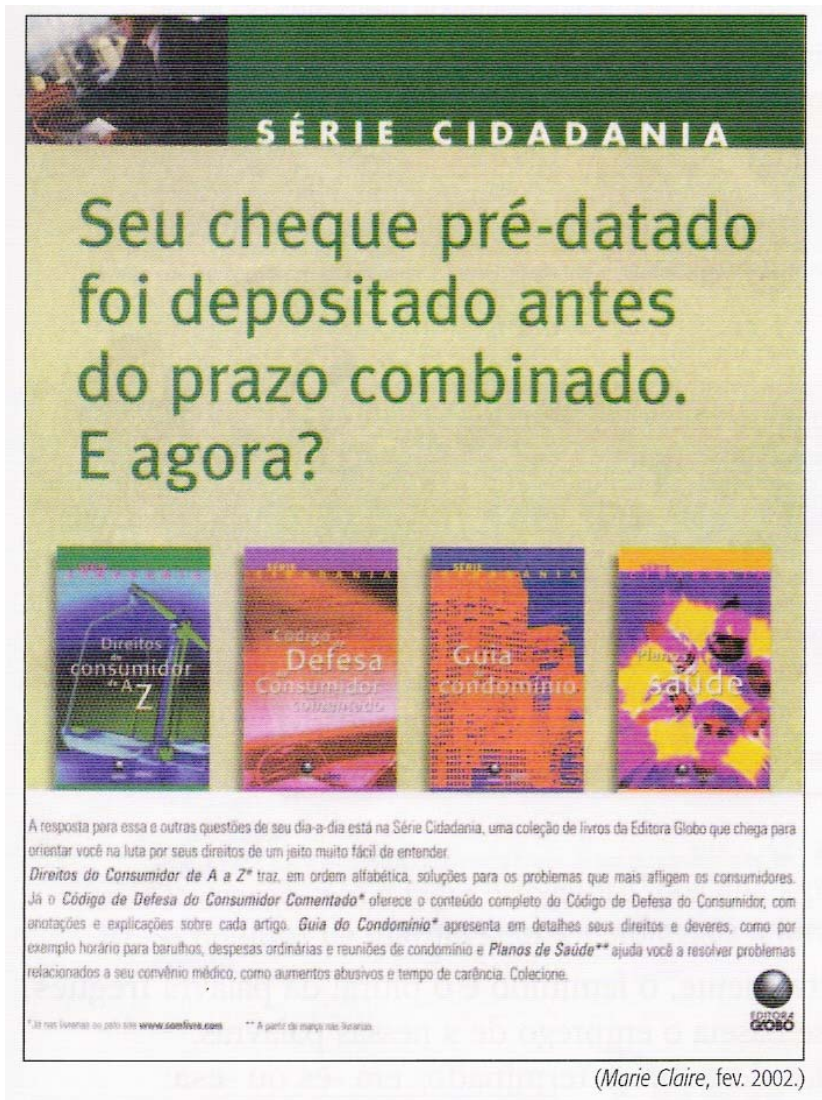

Leia as frases:

Alguém depositou seu cheque pré-datado antes do prazo combinado.

"Seu cheque pré-datado foi depositado antes do prazo combinado."

a) Qual das frases parece mostrar maior indignação com o fato de o cheque pré-datado ter sido depositado antes do prazo combinado?

2. Fonte: Cereja e Magalhães. Português: linguagens - $7^{\mathrm{a}}$ série - p. 67.

Notamos que este é um exercício o qual, indiretamente, explora o conceito de sinonímia estrutural que, segundo Ilari e Geraldi (1987), tradicionalmente ocorre quando optamos pelo uso de dada estrutura sintática, sem que haja alteração de sentido. Entretanto, assim como na sinonímia lexical, na estrutural, também não podemos prever a relação perfeita. Desse modo, é interessante fazer com que o aluno perceba que a escolha pela voz ativa ou passiva estará diretamente ligada a um efeito de sentido específico.

Em volumes direcionados ao Ensino Médio, tanto da obra Português: linguagens, quanto da Gramática reflexiva: texto, semântica e interação, os autores trazem a seção Semântica e Interação, na qual é feita uma retomada dos conteúdos abordados no respectivo capítulo, porém dando ênfase ao discurso, isto é, às particularidades em que os textos em estudo se deram.

Portanto, ao apresentar o texto, os autores, na maioria das vezes, propõem um trabalho detalhado de interpretação e leitura deste, seja de enunciados verbais ou não-verbais 
para, em seguida, puxar questionamentos que investigam o sentido daqueles enunciados, bem como outras possibilidades nele presentes.

Há ainda um capítulo que, de forma mais sistematizada, trata de conceitos da semântica lexical, como sinonímia, antonímia, hiponímia, hiperonímia, polissemia e ambiguidade.

No caso da relação de sinonímia, o tratamento dado pelos autores, em ambas as obras, no capítulo Introdução à Semântica, parte de exemplos que visam à comparação de enunciados em que há a substituição de termos "sinônimos", para em seguida, expor o conceito clássico de sinônimo: "[...] são palavras de sentidos aproximados que podem ser substituídas uma pela outra em diferentes contextos” (CEREJA; MAGALHÃES, 2005, p. 388).

Se o tratamento dado à temática se limitasse à apresentação do conceito, diríamos que a abordagem teria sido superficial, além de fazer com que o aluno pensasse na possibilidade de sinonímia perfeita. No entanto, os autores prosseguem:

[...] não existem sinônimos perfeitos e assim, a escolha entre dois sinônimos acaba dependendo de vários fatores [...] na linguagem cotidiana, as palavras furto e roubo, por exemplo, significam a mesma coisa; em linguagem jurídica, porém, roubo se aplica à situação em que a vítima sofre também algum tipo de violência. (CEREJA; MAGALHÃES, 2005, p.388).

De um modo geral, nas coleções citadas, paralelamente aos exercícios de sinonímia, práticas interpretativas que se utilizam de enunciados ambíguos são frequentes, portanto o termo ambiguidade é recorrente nos livros direcionados a todas as séries.

Apresentaremos, a seguir, de modo mais sistematizado, o tratamento atribuído a esse tema.

\section{MULTIPLICANDO OS SENTIDOS: AMBIGUIDADE}

Não é rara a utilização de termos ambíguos em enunciados da modalidade oral ou escrita da língua. Em alguns gêneros específicos, a exemplo de textos publicitários ou humorísticos, chega a ser um recurso produtivo na construção do efeito de sentido desejado. Por outro lado, em outros contextos, nos quais se exige uma linguagem objetiva, tal recurso passa a ser visto como um problema que afeta a clareza e o sentido do texto.

A ambiguidade é a característica de enunciados construídos de forma a possuir mais de um sentido. Segundo Ilari e Geraldi (1987), tal fato ocorre em diferentes níveis lexical, estrutural ou contextual -, o que depende da natureza do recurso responsável pelo efeito de múltiplos sentidos.

Segundo Pinkal (1995), a ambiguidade é lexical quando um termo, por si só, possui duplicidade de sentido, provocando a dupla interpretação do enunciado, o que pode ocorrer com os casos de homonímia (mesmo termo com dois sentidos diferentes e independentes - manga vs. manga) e de polissemia (mesmo termo com sentidos diferentes, porém, com alguma base em comum - universidade "prédio" vs. 
universidade "instituição”). Assim, o autor trata de apresentar testes que objetivam a diferenciação entre os casos de homonímia e polissemia.

Neste artigo, não iremos explicitar a diferença entre homonímia e polissemia ao tratar a ambiguidade lexical, pois não delimitamos como objetivo tal discussão teórica. Buscase questionar como e com que propósitos a ambiguidade pode ser abordada como um conteúdo a ser estudado na disciplina, de forma mais sistemática do que parece já ocorrer.

Para isso, retomemos a obra Português: linguagens, apresentando um exercício proposto para a $5^{\mathrm{a}}$ série, a partir de um texto publicado na Folha de São Paulo, que relaciona a linguagem verbal com a não-verbal, anunciando o próprio jornal, através de uma homenagem ao dia das mães:

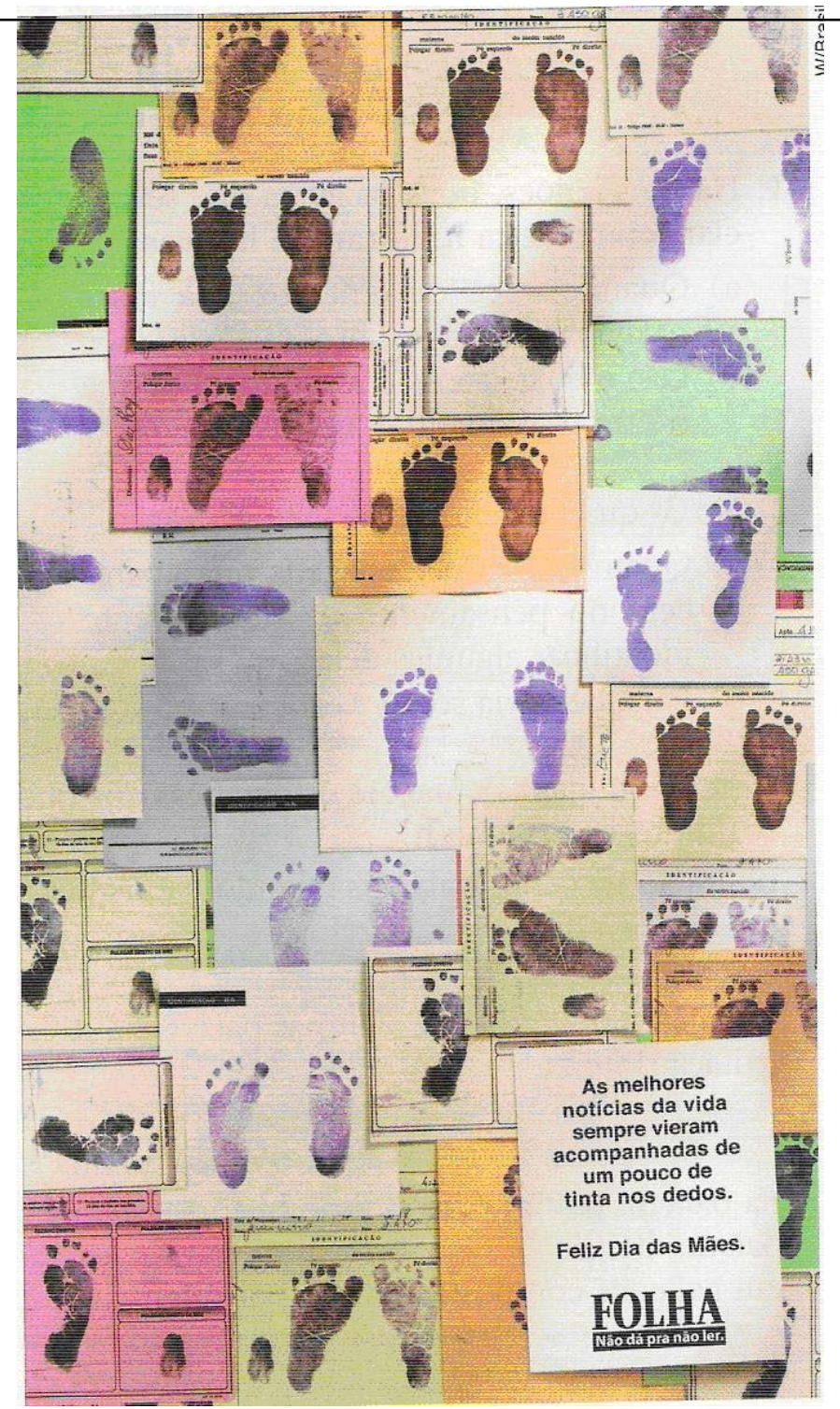

Quando lemos um jornal, é normal ficarmos com as mãos sujas de tinta. Observe o enunciado verbal do anúncio. Considerando-se o contexto, ele apresenta ambigüidade, isto é, dublo sentido. Ouais são esses sentidos?

3. Fonte: Cereja e Magalhães. Português: linguagens - 5a série - p. 69. 
Notamos, neste exercício, que o aluno/leitor deve observar a duplicidade da expressão "tinta nos dedos", referente tanto à "tinta deixada nas mãos dos leitores da Folha ao manusearem o jornal” quanto à "tinta deixada nos pés dos bebês no momento em que nascem”. Isso significa dizer que ler as notícias de um jornal como a Folha tem o grau de importância comparado ao nascimento de um filho. Para se chegar a essa interpretação, é necessário que se discuta muito o sentido do texto.

Ainda nesse jogo de leituras entre o sentido literal e não-literal, na série seguinte, encontramos o anúncio da Chevrolet S 10:

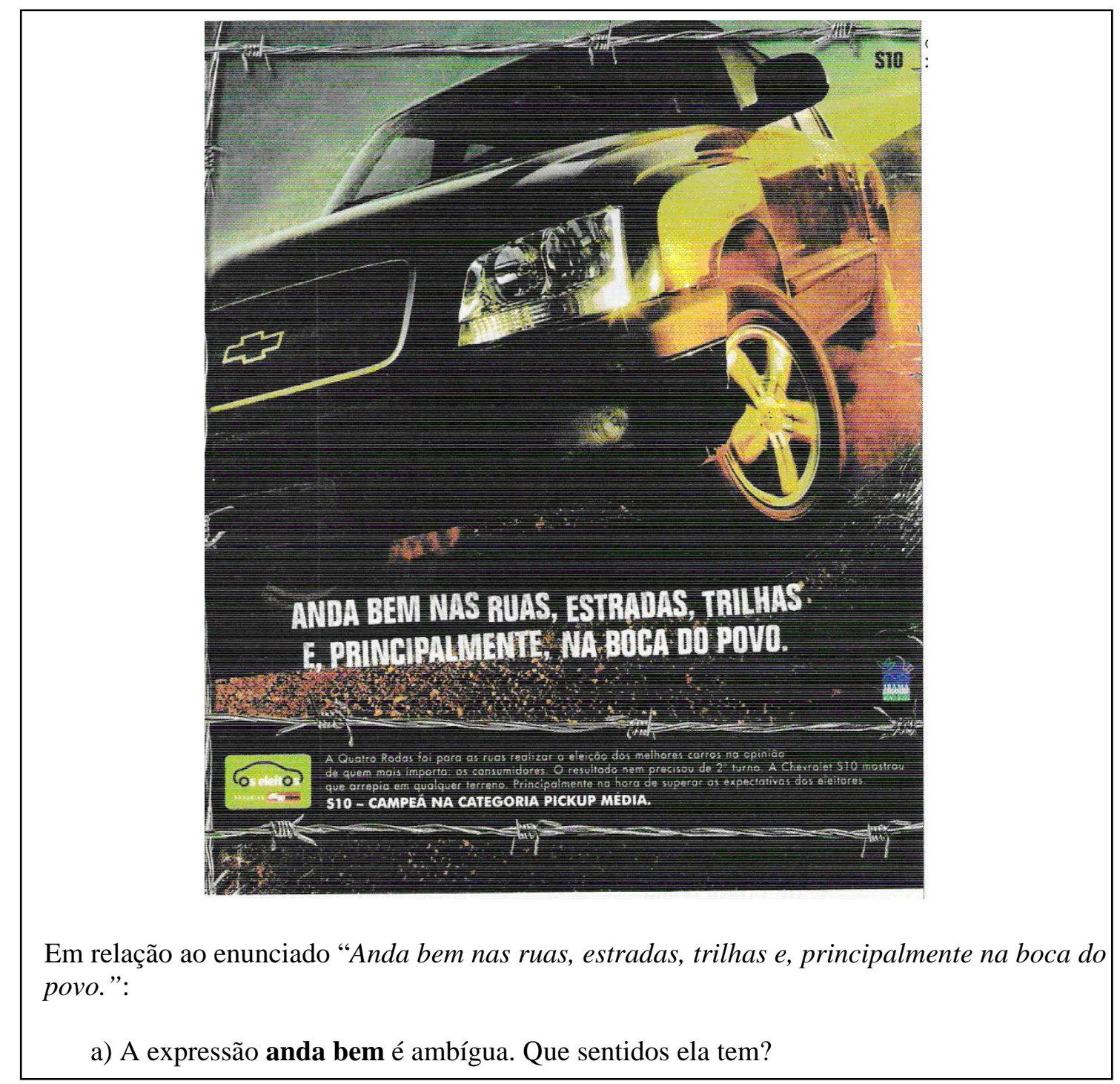

4. Fonte: Cereja e Magalhães. Português: linguagens - 6 ${ }^{\mathrm{a}}$ série - p. 234.

Observamos que, nesta atividade, o aluno/leitor deve perceber a ambiguidade do verbo “andar”, que está explicitamente usado com o sentido de deslocamento, quando tem como complemento adverbial nas ruas, estradas, trilhas, mas esse não é o seu sentido quando reaparece de forma implícita com o complemento na boca do povo. Neste último, trata-se da expressão de linguagem figurada "andar na boca do povo". O que ocorre no texto é uma ruptura, isto é, uma desobediência às regras de paralelismo, pois o 
conectivo $e$ está adicionando os dois complementos, como se fossem complementos da mesma natureza para o mesmo verbo, enquanto o que de fato acontece é a ocorrência do mesmo verbo com dois diferentes sentidos. No entanto, esses sentidos não se excluem e a conclusão do texto se faz pela associação de andar 1 e andar 2, o que reforça duas qualidades do produto: ser potente em termos mecânicos e ter popularidade.

No Ensino Médio, no capítulo destinado à Introdução à Semântica, os autores apresentam a polissemia, iniciando pela comparação de enunciados, para, em seguida, conceituar tal fenômeno, como "[...] é a propriedade que a palavra tem de apresentar vários sentidos.” (CEREJA; MAGALHÃES, 2005, p. 389).

Na sequência, fazem o mesmo para o termo ambiguidade, cuja definição dada é “[...] a duplicidade de sentidos que pode haver em um texto, verbal ou não verbal." (CEREJA; MAGALHÃES, 2005, p. 391). É importante ressaltar que os autores não consideram a relação entre ambiguidade e polissemia, ignorando o fato de que polissemia é um tipo de ambiguidade lexical, como já citado no início da seção.

No entanto, essa superficialidade teórica não interfere na proposta dos autores, que é a exploração de atividades reflexivas. Além disso, há o cuidado no que concerne à diferenciação entre ambiguidade como recurso de construção e ambiguidade como problema de construção.

É importante que ambiguidade seja de fato um tema explorado como recurso de construção, uma vez que isso é visível nos textos que circulam na sociedade, ao invés de ser exposta apenas como um defeito textual, o que ocorre nas demais obras investigadas.

\section{EXTRAPOLANDO A MORFOSSINTAXE}

Nesta última seção, apresentaremos atividades que associam conhecimento gramatical, de cunho morfológico ou sintático, à interpretação de sentidos.

Em Português: linguagens $-5^{\mathrm{a}}$ série, inicia-se um tipo de exercício, que prosseguirá nos demais volumes das séries subsequentes, sobre o estudo das classes gramaticais. Após a conceituação da classe, bem como de seus aspectos morfológicos (variações), a seção Semântica e Discurso aborda a questão do uso de determinada classe, promovendo a reflexão sobre a mudança de sentido em diferentes usos.

Por exemplo, em relação à classe dos artigos, selecionamos as seguintes atividades. 
Imagine a seguinte situação: uma garota chega em casa e diz uma ou outra destas frases:

- Mãe, achei o anel.

- Mãe, achei um anel.

a) Qual das duas frases dá a entender que a garota havia perdido um determinado anel?

b) Qual das duas frases dá a entender que a garota achou um anel qualquer, indeterminado?

Explique a diferença de sentido entre as duas frases de cada item a seguir, considerando a presença ou não do artigo definido.

a) Toda casa tinha água encanada.

Toda a casa tinha água encanada.

b) Estas pranchas foram usadas pelos surfistas do Rio de Janeiro.

Estas pranchas foram usadas por surfistas do Rio de Janeiro.

c) Encontro amigos em todos os lugares aonde vou.

Encontro os amigos em todos os lugares aonde vou.

5. Fonte: Cereja e Magalhães. Português: linguagens- $5^{\mathrm{a}}$ série - p. 167.

Tradicionalmente, o ensino de Língua Portuguesa visa à memorização da nomenclatura, o que requer que o aluno saiba identificar a classe dos artigos em relação às demais classes de palavras e classificá-los como definido e indefinido. Tendo como fim esse estudo classificatório, os exercícios costumam ser fragmentados e direcionados ao seu propósito. A atividade acima extrapola esse nível, quando leva o aluno ao questionamento do sentido que cada tipo de artigo ou a ausência do mesmo atribui ao enunciado. Parece simples, mas se trata de um incipiente conhecimento semântico da função dos artigos, antes limitado a noções morfológicas. Desse modo, encontramos o avanço tão necessário no ensino de gramática, chamado anteriormente de necessidade de inserção da semântica no ensino da língua materna.

O mesmo ocorre quando o conteúdo gramatical passa da análise morfológica para a sintática. No volume da $7^{\mathrm{a}}$ série, encontramos:

Leia as frases a seguir e compare-as quanto ao sentido.

- O menino doente não pôde participar da competição esportiva.

- O menino, doente, não pode participar da competição esportiva.

a) Qual a diferença de sentido entre elas?

b) Qual é a função sintática da palavra doente em cada uma das frases?

6. Fonte: Cereja e Magalhães. Português: linguagens- $7^{\mathrm{a}}$ série - p. 91.

Tradicionalmente, o foco do exercício seria a função sintática dos termos, no caso da comparação entre os enunciados, do termo comum a eles - doente. O aluno, nesta situação, ou aprende algum "macete" que o faça acertar a nomenclatura desejada, como a presença de vírgulas, ou não compreende as diferentes funções sintáticas - adjunto adnominal e predicativo - pois nem mesmo percebe o sentido dos enunciados.

Associar a interpretação à classificação, ao menos já seria um avanço em direção ao questionamento sobre o sentido dos próprios termos - adjunto e predicativo. 
Outra proposta interessante é a associação da organização sintática do enunciado com a duplicidade de sentido provocada, o que já denominamos na seção anterior como ambiguidade estrutural. Ainda no volume da $7^{\mathrm{a}}$ série, encontramos a atividade que segue.

Compare estas frases quanto ao sentido:

- De uniforme, o professor de Educação Física atendeu os alunos.

- O professor de Educação Física atendeu os alunos de uniforme.

- O professor de Educação Física, de uniforme, atendeu os alunos.

a) Em qual ou quais delas a expressão de uniforme refere-se apenas ao professor de Educação Física?

Se o contexto não esclarecer a intenção do locutor, a frase "O professor de Educação Física atendeu os alunos de uniforme” pode ser ambígua, isto é, ter duplo sentido.

a) Quais são esses sentidos?

b) Indique o tipo de predicado dessa oração, no caso de um ou outro sentido.

7. Fonte: Cereja e Magalhães. Português: linguagens- $7^{\text {a }}$ série - p. 92.

Também no enfoque tradicional, um exercício pautado em tais enunciados enfatizaria apenas as cobranças acerca da classificação sintática, visto que a expressão de uniforme ora está como adjunto adnominal, ora como predicativo do sujeito. No entanto, o enfoque dado nesta proposta é a percepção de que diferentes construções acarretam diferentes sentidos, ou mesmo provocam ambiguidade. Além disso, explica-se que a função sintática não se altera sem uma justificativa que não esteja na interpretação semântica da sentença.

Na mesma concepção, encontramos atividades que visam ao estudo das conjunções, a partir do valor ou dos valores semânticos de tal classe. Por exemplo, há exercício que propõe ao aluno a leitura de vários períodos compostos, conectados pelo termo $e$, com 0 objetivo de que reflitam sobre os diferentes sentidos que a conjunção assume em cada contexto. Assim, apresentam-se os seguintes exemplos em que a presença de $e$ indica, respectivamente, ideia de adversidade, conclusão, finalidade e explicação enfática.

a) Disseram estar famintos e não comeram nada.

b) Luciana saiu de casa bem cedo e já deve estar chegando ao interior.

c) Pensou em comprar flores e dá-las de presente para a mãe.

d) O garoto disse: "Não vou dar banho no cachorro hoje." "E eu, nunca”, respondeu a irmã.

8. Fonte: Cereja e Magalhães. Português: linguagens - $7^{\mathrm{a}}$ série - p. 218.

Chamar a atenção para o valor semântico das conjunções e, mais que isso, para o fato de que uma conjunção nem sempre estabelece uma única relação de sentido, é o passo primordial para a necessária mudança no estudo gramatical, quando este visa à compreensão da estrutura da língua no âmbito das relações entre as orações. Dessa forma, deixa-se de trabalhar com a apresentação de períodos compostos prontos, com fins de classificação sintática, para iniciar um trabalho em que o aluno aprenda a formar tais períodos, o que requer processar algumas etapas, tais como: perceber a relação de 
sentido entre as ideias a serem conectadas, selecionar entre várias das conjunções existentes na língua como recurso para estabelecer tal conexão e, por fim, compreender a versatilidade de uma mesma conjunção, que, em diferentes enunciados, possui diferentes valores semânticos. Enfim, traçar esse caminho significa substituir uma análise essencialmente sintática por uma análise semântica, ou semântico-sintática, ao menos quando se trata do estudo das orações coordenadas e das subordinadas adverbiais. Além disso, fazemos uso da conjunção na concepção textual, que insere essa classe naquilo que se denominam operadores argumentativos, termo que, segundo Koch (2000, p. 30), “[...] foi cunhado por O. Ducrot, [...] para designar certos elementos da gramática de uma língua que têm por função indicar a força argumentativa dos enunciados, a direção (sentido) para o qual apontam”.

\section{CONSIDERAÇÕES FINAIS}

Historicamente, no Brasil, foi a partir da década de 1950, segundo Soares (2002), que o ensino de Língua Portuguesa sofreu mudanças que vão desde alterações em sua nomenclatura até o recrutamento seletivo de professores, devido ao aumento do alunado - resultado do direito à escolarização.

Nesse contexto, o livro didático ganhou um espaço importante na sala de aula, pois, além de propor uma linha de trabalho e uma metodologia de ensino, serve de suporte ao desenvolvimento da proposta pedagógica.

Pesquisas anteriores sobre o livro didático sugerem que a maioria deles tem sido elaborada sob o enfoque tradicional, voltado quase que exclusivamente às classificações morfológico-sintáticas e ao trabalho descontextualizado de textos. Tendo isso como pressuposto, poderia ser esperado tal resultado na análise proposta neste artigo. No entanto, o material didático de Cereja e Magalhães apresentou uma proposta diferenciada, considerando tanto a seleção e a organização dos conteúdos quanto a metodologia.

Acreditamos que, para desenvolver um trabalho com enfoque linguístico, conforme sugerido pelos PCNs, é necessária uma abordagem a partir do que se denomina gramática reflexiva. Afinal, a metodologia da gramática reflexiva consiste em perguntar quais as alternativas entre os recursos linguísticos disponíveis foram utilizadas na construção do enunciado e em comparar os efeitos de sentido nas situações de interação comunicativa. Portanto, essa é uma metodologia que, segundo Travaglia (2002, p. 150) “[...] se preocupa mais com a forma de atuar usando a língua do que com uma classificação dos elementos lingüísticos e o ensino da nomenclatura que consubstancia essa classificação.”.

Logo, essas atividades permitem que os alunos, na condição de leitores ou de autores, pensem no efeito de sentido desejado, a fim de se buscar o recurso mais adequado à situação em que sua interpretação ou seu texto aparecerá. Consequentemente, o aluno torna-se cada vez mais consciente de que a escolha dos elementos da língua é regida pela adequação dos recursos e das instruções de sentido que abarcam os propósitos dos usuários da língua em dada situação comunicativa. 
Por fim, é preciso considerarmos a importância da Semântica no ensino de Língua Portuguesa como um processo que está apenas iniciando e que requer, portanto, além de muita pesquisa, maior eficácia na aplicação pedagógica imediata do conhecimento advindo das investigações acadêmicas.

\section{REFERÊNCIAS}

BRASIL. Secretaria de Educação Fundamental. Parâmetros Curriculares Nacionais de Língua Portuguesa. Brasília: MEC/SEF, 1997.

CEREJA, William Roberto; MAGALHÃES, Thereza Cochar. Português: linguagens. $2^{a}$ ed. Ensino Fundamental. São Paulo: Atual, 2006.

William Roberto; MAGALHÃES, Thereza Cochar. Português: linguagens. $4^{\text {a }}$ ed. Ensino Médio. São Paulo: Atual, 2004.

William Roberto; MAGALHÃES, Thereza Cochar. Gramática reflexiva: texto, semântica e interação. $2^{a}$ ed. São Paulo: Atual, 2005.

ILARI, Rodolfo. A lingüística e o ensino da língua portuguesa. São Paulo, Martins Fontes, 1997. 1987. Rodolfo; GERALDI, João Wanderley. Semântica. 3a ed. São Paulo: Ática,

KOCH, Ingedore. O texto e a construção dos sentidos. São Paulo, Contexto, 2000.

MURPHY, M. Lynne. Knowledge of words versus knowledge about words: the conceptual basis lexical relations In: Bert Peeters (ed.), The lexicon/encyclopedia interface. (Current research in the semantics-pragmatics interface 5.) Amsterdam: Elsevier, 2000: 317-48.

PEREIRA, Maria Teresa; HENRIQUES, Cláudio Cezar (orgs.) Língua e transdiciplinaridade: rumos, conexões, sentidos. São Paulo: Contexto, 2002.

PINKAL, M. Logic and Lexicon. Netherland: Kluwer Academic Publishers, 1995.

SOARES, Magda. Português na escola: história de uma disciplina curricular. In: BAGNO, Marcos (org.) Lingüística da norma. São Paulo: Loyola, p. 155-177, 2002.

TRAVAGLIA, Luiz Carlos. Gramática e interação: uma proposta para o ensino da gramática no $1^{\circ}$ e $2^{\circ}$ graus. 8. ed. São Paulo: Cortez, 2002. 